\title{
CONDUTIVIDADE ELÉTRICA EM SEMENTES DE RÚCULA ${ }^{1}$
}

\author{
SALVADOR BARROS TORRES ${ }^{2}$, RAFAELA ALVES PEREIRA²
}

\begin{abstract}
RESUMO - O teste de condutividade elétrica da solução de embebição é recomendado para avaliar o vigor de sementes de ervilha e indicado para outras espécies, mas ainda há necessidade da continuidade de estudos sobre o assunto. A pesquisa teve como objetivo estabelecer ajustes na metodologia do teste de condutividade elétrica para avaliar o potencial fisiológico de sementes de rúcula (Eruca sativa L.). Para isso, o estudo foi conduzido utilizando dois cultivares de sementes de rúcula, Cultivada e Folha Larga, cada um representado por cinco lotes de sementes. Foram realizados os testes de germinação, primeira contagem de germinação, envelhecimento acelerado, emergência de plântulas em campo e o teste de condutividade elétrica, usando-se as temperaturas de 20, 25 e $30^{\circ} \mathrm{C}$; volumes de água para embebição de 25,50 e $75 \mathrm{~mL}$; amostras de 25 e 50 sementes; e períodos de embebição de 1, 2, 4, 8, 12, 16, 20 e 24 horas. Conclui-se que o teste de condutividade elétrica é eficiente para avaliação do vigor de sementes de rúcula quando conduzido com 50 sementes imersas em $50 \mathrm{~mL}$ de água desionizada a $25^{\circ} \mathrm{C}$, após oito horas de embebição.
\end{abstract}

Termos para indexação: Eruca sativa, potencial fisiológico, vigor, qualidade de sementes.

\section{ELECTRICAL CONDUCTIVITY IN SALAD ROCKET SEEDS}

\begin{abstract}
Electrical conductivity has been recommended for evaluating seed vigor in peas and other species although research is still needed to improve procedures. The objective of this study was to develop methodology for the electrical conductivity test to evaluate the physiological potential of salad rocket (Eruca sativa L.) seeds. Five seed lots were used for each of two cultivars of salad rocket, "Cultivada" and "Folha Larga". The following tests were made: standard germination, first germination count, accelerated ageing, field emergence and variations in the electrical conductivity test $\left(25\right.$ or 50 seeds imbibed in $25 \mathrm{~mL}, 50 \mathrm{~mL}$ or $75 \mathrm{~mL}$ of water; at $20{ }^{\circ} \mathrm{C}$, $25^{\circ} \mathrm{C}$ and $30^{\circ} \mathrm{C}$; for $1,2,4,8,12,16,20$ and 24 hours). The results confirmed the efficiency of the electrical conductivity test to evaluate salad rocket seed vigor. The best combination was 50 seeds immersed in $50 \mathrm{~mL}$ of deionized water at $25^{\circ} \mathrm{C}$, for eight hours.
\end{abstract}

Index terms: Eruca sativa, physiological potential, vigor, seed quality.

\footnotetext{
${ }^{1}$ Submetido em 21/03/2010. Aceito para publicação em 25/08/2010.

${ }^{2}$ Eng. Agr., Dr., Pesquisador da EMPARN e Prof. Colaborador do Departamento de Ciências Vegetais, UFERSA, Caixa Postal 137, 59625-
}

900, Mossoró/RN, sbtorres@ufersa.edu.br

${ }^{3}$ Graduanda em Agronomia, UFERSA, Mossoró/RN, Bolsista CNPq, faela.alves@hotmail.com 


\section{INTRODUÇÃO}

Os testes de vigor têm se constituído em ferramentas de uso cada vez mais rotineiro pela indústria de sementes, visando à determinação do potencial fisiológico. As empresas produtoras e as instituições oficiais têm incluído esses testes em programas internos de controle de qualidade e, ou para garantia da qualidade de sementes destinadas à comercialização. Segundo Marcos Filho (2005), esses testes procuram detectar diferenças significativas no potencial fisiológico de lotes com geminação semelhante, fornecendo informações adicionais às proporcionadas pelo teste de germinação. Paralelamente, espera-se que os resultados permitam distinguir com segurança os lotes de alto dos de baixo vigor e que as diferenças detectadas estejam relacionadas ao comportamento das sementes durante o armazenamento e o desempenho em campo.

A maior limitação do teste de germinação, segundo Hampton e TeKrony (1995), é a sua inabilidade para detectar diferenças de qualidade entre lotes com alta germinação. Por isso, tem-se procurado aperfeiçoar procedimentos com o intuito de avaliar o vigor de sementes ou de lotes identificando possíveis diferenças no potencial fisiológico de lotes que apresentem germinação semelhantes, fornecendo informações complementares às obtidas no teste de germinação, dentro de programas de controle da qualidade das empresas produtoras de sementes de hortaliças.

Dentre os testes de vigor, o de condutividade elétrica, inicialmente desenvolvido para sementes de ervilha (Matthews e Bradnock, 1967), tem sido usado intensivamente para avaliar o vigor dessa espécie, em várias partes do mundo (Hampton e TeKrony, 1995), bem como tem sido usado para várias outras espécies, como soja (Vieira e Krzyzanowski, 1999; Marcos Filho e Vieira, 2009).

Em termos de padronização, o teste é considerado promissor. Entretanto, estudos conduzidos pelo Comitê de Vigor da ISTA foram constatadas variações nos resultados entre laboratórios, devido a problemas de metodologia (Perry, 1981). De fato, estudos têm demonstrado que vários fatores podem afetar os resultados desse teste, entre os quais se destacam: a temperatura durante a embebição e avaliação (Panobianco e Marcos Filho, 2001), quantidade de água (Loeffler et al., 1988; Rodo e Marcos Filho, 2003), genótipo (Panobianco e Vieira, 1996; Torres e Marcos Filho, 2005) e número de sementes e período de embebição (Alves e Sá, 2009).
Para nossas condições, a disponibilidade de informações para a avaliação do vigor de sementes de rúcula ainda é escassa. $\mathrm{O}$ exame da literatura indica que Ramos et al. (2004) destacaram a eficiência do teste de envelhecimento acelerado $\left(41{ }^{\circ} \mathrm{C} / 48 \mathrm{~h}\right)$; já Goulart e Tillmann (2007) verificaram que a combinação $41{ }^{\circ} \mathrm{C}$, com teor de água das sementes de $20 \%$ por $24 \mathrm{~h}$ para condução do teste de deterioração controlada é eficiente para avaliar o potencial fisiológico de sementes de rúcula. Recentemente, Alves e Sá (2009), verificaram que o teste de condutividade elétrica, utilizando a combinação 50 sementes em $50 \mathrm{~mL}$ de água por quatro horas, a $25^{\circ} \mathrm{C}$, constituiu-se na condição mais adequada para a separação de lotes de sementes de rúcula em diferentes níveis de vigor.

Portanto, em função do exposto, o trabalho teve como objetivo estabelecer ajustes na metodologia do teste de condutividade elétrica para avaliar o vigor de sementes de rúcula.

\section{MATERIAL E MÉTODOS}

Durante o período de julho de 2008 a agosto de 2009, foi desenvolvido no Laboratório de Análise de Sementes do Departamento de Ciências Vegetais da Universidade Federal Rural do Semiárido (UFERSA), o experimento utilizando-se sementes de rúcula (Eruca sativa L.) cultivares Folha Larga e Cultivada, cada um representado por cinco lotes, provenientes da empresa ISLA Sementes Ltda, produzidos no ano agrícola 2007/2008. Durante o período experimental as sementes foram mantidas em sacos de papel e armazenadas em ambiente controlado $\left(20{ }^{\circ} \mathrm{C}\right.$ e $55 \%$ de umidade relativa do ar) $\mathrm{O}$ estudo compreendeu as seguintes avaliações:

Grau de umidade - realizado pelo método da estufa a $105 \pm 3{ }^{\circ} \mathrm{C}$, durante 24 horas, de acordo com as Regras para Análise de Sementes - RAS (Brasil, 1992), utilizando-se duas subamostras de $2 \mathrm{~g}$ de sementes para cada lote. Os resultados foram expressos em porcentagem (base úmida) por lote.

Germinação - quatro repetições de 50 sementes por lote foram distribuídas sobre duas folhas de papel mataborrão, umedecidas com água equivalente a 2,5 vezes o peso do substrato seco e colocado no interior de caixa de plástico transparente $(11 \times 11 \times 3,5 \mathrm{~cm})$. Após a semeadura, as caixas foram tampadas e mantidas em câmara de germinação a 20 ${ }^{\circ} \mathrm{C}$. As avaliações foram efetuadas aos quatro e sete dias (Brasil, 1992). 
Primeira contagem de germinação - realizada conjuntamente com o teste de germinação, computandose a porcentagem de plântulas normais obtidas no quarto dia após a instalação do teste (Brasil, 1992).

Envelhecimento acelerado - foi utilizado o método da caixa $(11 \times 11 \times 3,5 \mathrm{~cm})$ de plástico (McDonald e Phaneendranath, 1978), onde as sementes foram distribuídas em camada única sobre a tela, em quantidade mínima suficiente para instalar o teste de germinação e determinar o teor de água das mesmas. No fundo das caixas foram colocados $40 \mathrm{~mL}$ de água destilada. As caixas com as sementes foram mantidas em câmara de germinação, a $41{ }^{\circ} \mathrm{C}$ por 48 horas (Goulart e Tillmann, 2007). Após o período de exposição, as sementes foram colocadas para germinar e a avaliação realizada no quarto dia, após a semeadura (Brasil, 1992). Paralelamente, foi determinado pelo método da estufa, o teor de água das sementes após o envelhecimento.

Emergência de plântulas: quatro repetições de 50 sementes foram semeadas em canteiros no espaçamento de 10 x $20 \mathrm{~cm}$, fazendo uso de irrigação quando necessário. A avaliação foi realizada aos 15 dias após a semeadura, computando-se as porcentagens de plântulas emergidas (Nakagawa, 1994).

Condutividade elétrica: foram estudadas variações no número de sementes ( 25 e 50 ), volume de água de embebição $(50$ e $75 \mathrm{~mL})$ e na temperatura $\left(20,25\right.$ e $\left.30^{\circ} \mathrm{C}\right)$ durante $1,2,4,8,12,16,20$, e 24 horas de embebição. $\mathrm{O}$ teste foi conduzido pelo método de massa, utilizandose quatro repetições de sementes puras para cada lote. As sementes foram pesadas (precisão de 0,001g) e colocadas para embeber em copos de plástico (capacidade de $200 \mathrm{~mL}$ ) contendo água desionizada e mantidos em germinador durante cada período de embebição. As leituras da condutividade elétrica foram realizadas em condutivímetro DIGIMED DM-31 e os valores expressos em uS.cm ${ }^{1} \cdot \mathrm{g}^{1}$ de sementes.

Utilizou-se o delineamento experimental inteiramente casualizado com quatro repetições, separadamente para cada cultivar e teste conduzido, avaliando-se os efeitos de lotes. As médias foram comparadas pelo teste de Tukey, no nível de $5 \%$ de probabilidade.

\section{RESULTADOS E DISCUSSÃO}

A qualidade inicial dos lotes de sementes de rúcula foi avaliada pelos testes de germinação, primeira contagem, envelhecimento acelerado e emergência das plântulas, além da determinação do grau de umidade (Tabela 1).

TABELA 1. Grau de umidade, germinação, primeira contagem, envelhecimento acelerado e emergência de plântulas e respectivos coeficientes de variação, de lotes de sementes de rúcula, cultivares Cultivada e Folha Larga.

\begin{tabular}{|c|c|c|c|c|c|c|}
\hline \multirow[t]{2}{*}{ Cultivares } & \multirow[t]{2}{*}{ Lotes } & $\begin{array}{l}\text { Grau de } \\
\text { umidade }\end{array}$ & Germinação & $\begin{array}{l}\text { Primeira } \\
\text { contagem }\end{array}$ & $\begin{array}{l}\text { Envelhecimento } \\
\text { acelerado }\end{array}$ & $\begin{array}{l}\text { Emergência de } \\
\text { plântulas }\end{array}$ \\
\hline & & \multicolumn{5}{|c|}{ 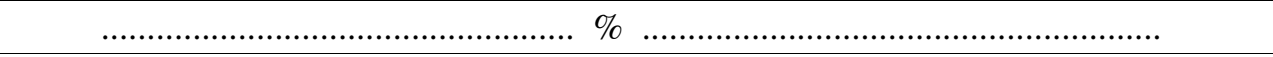 } \\
\hline \multirow{5}{*}{ Cultivada } & 1 & 5,0 & $84 \mathrm{~b}$ & $81 \mathrm{~b}$ & $70 \mathrm{c}$ & $70 \mathrm{c}$ \\
\hline & 2 & 6,6 & 98 a & 89 a & 84 a & $84 \mathrm{a}$ \\
\hline & 3 & 5,2 & $95 \mathrm{a}$ & $87 \mathrm{a}$ & $82 \mathrm{a}$ & $80 \mathrm{a}$ \\
\hline & 4 & 5,4 & 94 a & $80 \mathrm{~b}$ & $76 \mathrm{~b}$ & $76 \mathrm{~b}$ \\
\hline & 5 & 6,8 & $96 \mathrm{a}$ & $86 a$ & $78 \mathrm{ab}$ & $82 \mathrm{a}$ \\
\hline C.V.(\%) & & - & 4,16 & 8,60 & 5,73 & 12,39 \\
\hline \multirow{5}{*}{ Folha Larga } & 6 & 6,6 & 99 a & $98 \mathrm{a}$ & $79 a$ & $92 \mathrm{a}$ \\
\hline & 7 & 5,5 & $95 \mathrm{a}$ & $88 \mathrm{~b}$ & $70 \mathrm{~b}$ & $86 \mathrm{~b}$ \\
\hline & 8 & 6,7 & $96 \mathrm{a}$ & $92 \mathrm{a}$ & $79 a$ & $89 \mathrm{ab}$ \\
\hline & 9 & 6,8 & $96 \mathrm{a}$ & $86 \mathrm{~b}$ & $72 b$ & $84 \mathrm{~b}$ \\
\hline & 10 & 6,0 & $98 \mathrm{a}$ & $94 \mathrm{a}$ & $82 \mathrm{a}$ & $90 \mathrm{a}$ \\
\hline C.V.(\%) & & - & 2,96 & 2,39 & 8,75 & 28,66 \\
\hline
\end{tabular}

Comparação de médias dentro de cada coluna pelo teste de Tukey não diferem entre si a 5\% de probabilidade. 
Verifica-se que houve uniformidade no grau de umidade das sementes, uma vez que a variação entre os lotes foi de 1,8 e 1,3 pontos percentuais para os lotes de sementes dos cultivares Cultivada e Folha Larga, respectivamente. Essa variação no grau de umidade das sementes é aceitável, uma vez que está abaixo da variação máxima admitida, ou seja, 2 pontos percentuais (Marcos Filho, 1999).

O teste de germinação indicou o lote 1 do cultivar Cultivada como de baixa qualidade, enquanto os demais foram considerados como de alto potencial de desempenho, não diferindo entre si. Para os lotes do cultivar Folha Larga não houve diferenças no potencial fisiológico avaliado pelo teste de germinação. Segundo Marcos Filho (1999), é importante e coerente a comparação de lotes de sementes com germinação semelhante e, de acordo com Powell (1986), preferencialmente situados na Fase I da curva de perda de viabilidade. Essa autora considera que a posição do lote dentro da Fase I determina seu nível de vigor. Neste estudo, todos os lotes apresentaram alta qualidade, com germinação variando entre 84 e $98 \%$, estando situados, portanto, na Fase I da curva de perda viabilidade da semente, caracterizada por ser relativamente longa e com poucas sementes mortas (Tabela 1).

Os resultados do teste de primeira contagem de germinação mostraram-se mais sensíveis que os de germinação, que classificou os lotes 1 e 4 do cultivar Cultivada como de baixa qualidade e os demais como de alto vigor. Os lotes 6, 8 e 10 do cultivar Folha Larga foram apontados como de qualidade superior, enquanto os lotes 7 e 9 de baixa qualidade. Segundo Bhering et al. (2000), com sementes de pepino, esse teste pode ser utilizado rotineiramente para se obter informações preliminares sobre o vigor de lotes de sementes dessa espécie.

O teste de envelhecimento acelerado indicou o lote 1 do cultivar Cultivada como de pior qualidade, concordando com os resultados obtidos nos testes de germinação e primeira contagem; por outro lado, os lotes 2 e 3 foram confirmados como de melhor qualidade. Para os lotes do Folha Larga, esse teste confirmou a superioridade dos lotes 6,8 e 10 e, de certa forma, a inferioridade dos lotes 7 e 9.

Os resultados do teste de emergência de plântulas indicaram baixa qualidade do lote 1 do cultivar Cultivada e a superioridade dos lotes 2, 3 e 5. Nos lotes do Folha Larga, 6 e 10 foram considerados como de alta qualidade fisiológica e os lotes 7 e 9 confirmados como de baixa qualidade.

A análise comparativa dos dados indicou que, de maneira geral, os testes foram eficientes na identificação dos lotes que ocupam posições extremas, ou seja, separaram, de maneira consistente, diferenças acentuadas no potencial fisiológico das sementes. Assim, podese afirmar que, com segurança, que o lote 1 do cultivar Cultivada foi o menos vigoroso em relação aos demais; já os lotes 6 e 10, do cultivar Folha Larga, foram os mais vigorosos, enquanto os demais apresentaram qualidade intermediária, ocupando posições diferentes de acordo com o teste realizado. A identificação de lotes com vigor intermediário pode sofrer variações em função da metodologia adotada, principalmente quando se tratam de lotes com diferenças pouco acentuadas (Kulik e Yaklich, 1982; Marcos Filho et al., 1984). Sendo assim, enfatiza-se a importância do uso de mais de um teste para se determinar o vigor de lotes de sementes (Marcos Filho, 1998), devido à influência dos métodos adotados e uso de situações especificas de estresse para estimar o comportamento relativo dos lotes em campo (TeKrony e Egli, 1977; Carvalho e Nakagawa, 2000).

Os resultados do teste de condutividade elétrica, envolvendo as combinações de número de sementes, quantidades de água e temperaturas, nos diferentes períodos de embebição, estão apresentados nas Tabelas de 2 a 7.

A análise dos resultados permitiu verificar, de maneira geral, que as diversas combinações de número de sementes e volumes de água para as temperaturas 20 , 25 e $30^{\circ} \mathrm{C}$, estudadas no teste de condutividade elétrica apresentaram semelhança na distinção dos lotes em relação ao seu potencial fisiológico. Assim, constatouse que ambos os procedimentos indicaram os lotes 2 e 5 do cultivar Cultivada e 6, 8 e 10 do cultivar Folha Larga como os mais vigorosos. Por outro lado, os lotes 1 e 4 do Cultivada e 7 e 9 do Folha Larga foram considerados os piores.

Portanto, verificou-se que independentemente da combinação número de sementes/quantidade de água/ temperatura utilizada, as informações fornecidas pelo teste, para ambos os cultivares, tiveram relação direta com os testes de avaliação da qualidade inicial dos lotes de sementes (Tabela 1). Informações nesse sentido, também, foram encontradas por Alves e Sá (2009), com sementes de rúcula, dos cultivares Cultivada e Gigante. De maneira semelhante, Dias et al. (1998), em sementes de feijão-devagem e quiabo, concluíram que o teste de condutividade elétrica mostrou-se eficiente para a avaliação do potencial fisiológico dessas sementes. 
TABELA 2. Condutividade elétrica $\left(\mu \mathrm{S} . \mathrm{cm}^{-1} \cdot \mathrm{g}^{-1}\right)$ utilizando as combinações 25 sementes $/ 50 \mathrm{~mL}$ e 50 sementes/50 mL, a $20^{\circ} \mathrm{C}$, respectivamente, de lotes de sementes de rúcula, cultivares Cultivada e Folha Larga, em cada período de embebição.

\begin{tabular}{|c|c|c|c|c|c|c|c|c|c|}
\hline \multirow{3}{*}{ Cultivares } & \multirow{3}{*}{ Lotes } & \multicolumn{8}{|c|}{ Períodos de embebição (h) } \\
\hline & & 1 & 2 & 4 & 8 & 12 & 16 & 20 & 24 \\
\hline & & \multicolumn{8}{|c|}{. 25 sementes $/ 50 \mathrm{~mL}$} \\
\hline \multirow{5}{*}{ Cultivada } & 1 & $54,7 \mathrm{~b}$ & $56,6 \mathrm{~b}$ & $71,9 \mathrm{~b}$ & $80,8 \mathrm{~b}$ & $91,0 \mathrm{~b}$ & $97,6 \mathrm{~b}$ & $110,5 \mathrm{~b}$ & $118,1 \mathrm{~b}$ \\
\hline & 2 & $31,9 \mathrm{a}$ & $36,9 \mathrm{a}$ & 46,6 a & $57,9 \mathrm{a}$ & $66,7 \mathrm{a}$ & $78,1 \mathrm{a}$ & 83,6 a & $92,7 \mathrm{a}$ \\
\hline & 3 & 33,3 a & $44,1 \mathrm{ab}$ & $59,3 \mathrm{~b}$ & $75,1 \mathrm{~b}$ & $89,0 \mathrm{~b}$ & $96,8 \mathrm{~b}$ & $100,7 \mathrm{~b}$ & $114,3 \mathrm{~b}$ \\
\hline & 4 & $36,1 \mathrm{a}$ & $46,8 \mathrm{a}$ & $69,9 \mathrm{~b}$ & $77,4 \mathrm{~b}$ & $91,3 \mathrm{~b}$ & $104,3 \mathrm{~b}$ & $113,3 \mathrm{~b}$ & $126,2 \mathrm{~b}$ \\
\hline & 5 & $35,6 \mathrm{a}$ & $46,6 \mathrm{a}$ & $46,4 \mathrm{a}$ & 59,9 a & $69,9 \mathrm{a}$ & $79,3 \mathrm{a}$ & $84,4 \mathrm{a}$ & $95,1 \mathrm{a}$ \\
\hline \multicolumn{10}{|c|}{ C.V. $(\%)=5,5$} \\
\hline \multirow{5}{*}{ Folha Larga } & 6 & $39,4 \mathrm{a}$ & $45,9 \mathrm{a}$ & $54,3 \mathrm{a}$ & $65,3 \mathrm{a}$ & $74,5 \mathrm{a}$ & $80,4 \mathrm{a}$ & $87,4 \mathrm{a}$ & $93,3 \mathrm{a}$ \\
\hline & 7 & $85,2 \mathrm{~b}$ & $90,8 \mathrm{~b}$ & $97,0 \mathrm{~b}$ & $99,8 \mathrm{~b}$ & $100,7 \mathrm{~b}$ & $102,5 \mathrm{ab}$ & $110,3 \mathrm{~b}$ & $120,7 \mathrm{~b}$ \\
\hline & 8 & $42,2 \mathrm{a}$ & $48,4 \mathrm{a}$ & $54,6 \mathrm{a}$ & $63,2 \mathrm{a}$ & $73,1 \mathrm{a}$ & $80,1 \mathrm{a}$ & $90,5 \mathrm{a}$ & $94,3 \mathrm{a}$ \\
\hline & 9 & $86,5 \mathrm{~b}$ & $92,6 \mathrm{~b}$ & $98,8 \mathrm{~b}$ & $122,6 \mathrm{bc}$ & $136,2 \mathrm{bc}$ & $140,4 \mathrm{bc}$ & $149,3 \mathrm{bc}$ & $162,5 \mathrm{bc}$ \\
\hline & 10 & $35,3 \mathrm{a}$ & $44,1 \mathrm{a}$ & $49,3 \mathrm{a}$ & $62,9 \mathrm{a}$ & $75,7 \mathrm{a}$ & $78,2 \mathrm{a}$ & $86,5 \mathrm{a}$ & $92,4 \mathrm{a}$ \\
\hline \multicolumn{10}{|c|}{ C.V. $(\%)=6,3$} \\
\hline \multicolumn{10}{|c|}{ 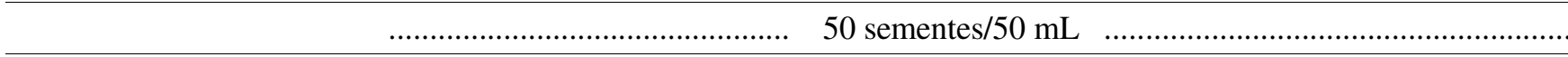 } \\
\hline \multirow{5}{*}{ Cultivada } & 1 & $55,7 \mathrm{~b}$ & $57,6 \mathrm{bc}$ & $72,9 \mathrm{bc}$ & $86,8 \mathrm{bc}$ & $92,0 \mathrm{bc}$ & $104,6 \mathrm{bc}$ & $113,5 \mathrm{bc}$ & $129,1 \mathrm{bc}$ \\
\hline & 2 & $32,9 \mathrm{a}$ & $37,9 \mathrm{a}$ & $47,6 \mathrm{a}$ & 58,9 a & $69,7 \mathrm{a}$ & $78,1 \mathrm{a}$ & 84,6 a & $93,7 \mathrm{a}$ \\
\hline & 3 & $34,3 \mathrm{a}$ & $45,1 \mathrm{~b}$ & $60,3 \mathrm{~b}$ & $72,1 \mathrm{~b}$ & $86,0 \mathrm{~b}$ & $90,8 \mathrm{~b}$ & $100,7 \mathrm{~b}$ & $105,3 \mathrm{~b}$ \\
\hline & 4 & $51,1 \mathrm{~b}$ & $57,8 \mathrm{bc}$ & $70,9 \mathrm{bc}$ & $88,4 \mathrm{bc}$ & $92,3 \mathrm{bc}$ & $109,3 \mathrm{bc}$ & $114,3 \mathrm{bc}$ & $127,2 \mathrm{bc}$ \\
\hline & 5 & $32,6 \mathrm{a}$ & $37,6 \mathrm{a}$ & $47,4 \mathrm{a}$ & $60,9 \mathrm{a}$ & $70,9 \mathrm{a}$ & 80,9 a & $85,4 \mathrm{a}$ & $96,1 \mathrm{a}$ \\
\hline \multicolumn{10}{|c|}{ C.V. $(\%)=3,9$} \\
\hline \multirow{5}{*}{ Folha Larga } & 6 & $40,4 \mathrm{a}$ & $46,9 \mathrm{a}$ & $53,3 \mathrm{a}$ & $68,3 \mathrm{a}$ & $76,5 \mathrm{a}$ & $82,4 \mathrm{a}$ & $89,4 \mathrm{a}$ & $95,3 \mathrm{a}$ \\
\hline & 7 & $87,2 \mathrm{~b}$ & $91,8 \mathrm{~b}$ & $95,0 \mathrm{~b}$ & $100,0 \mathrm{~b}$ & $108,7 \mathrm{~b}$ & $105,5 \mathrm{~b}$ & $111,3 \mathrm{~b}$ & $122,7 \mathrm{~b}$ \\
\hline & 8 & $44,2 \mathrm{a}$ & $50,4 \mathrm{a}$ & 56,6 a & $65,2 \mathrm{a}$ & $72,1 \mathrm{~b}$ & $81,1 \mathrm{a}$ & $92,5 \mathrm{a}$ & 96,3 a \\
\hline & 9 & $98,5 \mathrm{bc}$ & $108,0 \mathrm{bc}$ & $113,8 \mathrm{bc}$ & $125,6 \mathrm{bc}$ & $138,2 \mathrm{bc}$ & $141,4 \mathrm{bc}$ & $150,3 \mathrm{bc}$ & $164,5 \mathrm{bc}$ \\
\hline & 10 & $38,3 \mathrm{a}$ & $44,1 \mathrm{a}$ & $49,3 \mathrm{a}$ & $64,9 \mathrm{a}$ & $73,7 \mathrm{a}$ & $80,2 \mathrm{a}$ & $91,5 \mathrm{a}$ & 94,4 a \\
\hline
\end{tabular}

Comparação de médias dentro de cada coluna pelo teste de Tukey não diferem entre si a 5\% de probabilidade. 
TABELA 3. Condutividade elétrica $\left(\mu \mathrm{S} . \mathrm{cm}^{-1} \cdot \mathrm{g}^{-1}\right)$ utilizando as combinações 25 sementes $/ 75 \mathrm{~mL}$ e 50 sementes/75 mL, a $20^{\circ} \mathrm{C}$, respectivamente, de dez lotes de sementes de rúcula, cultivares Cultivada e Folha Larga, em cada período de embebição.

\begin{tabular}{|c|c|c|c|c|c|c|c|c|c|}
\hline \multirow{3}{*}{ Cultivares } & \multirow{3}{*}{ Lotes } & \multicolumn{8}{|c|}{ Períodos de embebição (h) } \\
\hline & & 1 & 2 & 4 & 8 & 12 & 16 & 20 & 24 \\
\hline & & \multicolumn{8}{|c|}{25 sementes $/ 75 \mathrm{~mL}$} \\
\hline \multirow{5}{*}{ Cultivada } & 1 & $52,7 \mathrm{~b}$ & $53,6 \mathrm{bc}$ & $70,9 \mathrm{bc}$ & $80,8 \mathrm{bc}$ & $90,0 \mathrm{bc}$ & $98,6 \mathrm{bc}$ & $108,5 \mathrm{bc}$ & $116,1 \mathrm{bc}$ \\
\hline & 2 & $30,9 \mathrm{a}$ & $33,9 \mathrm{a}$ & $45,6 \mathrm{a}$ & $56,9 \mathrm{a}$ & $65,7 \mathrm{a}$ & $73,1 \mathrm{a}$ & 81,6 a & $90,7 \mathrm{a}$ \\
\hline & 3 & $32,3 \mathrm{a}$ & $41,1 \mathrm{~b}$ & $58,3 \mathrm{~b}$ & $70,1 \mathrm{~b}$ & $84,0 \mathrm{~b}$ & $90,8 \mathrm{~b}$ & $97,7 \mathrm{~b}$ & $102,3 \mathrm{~b}$ \\
\hline & 4 & $49,1 \mathrm{~b}$ & $53,8 \mathrm{bc}$ & $68,9 \mathrm{bc}$ & 83,4 bc & $90,3 \mathrm{bc}$ & $100,3 \mathrm{bc}$ & $111,3 \mathrm{bc}$ & $119,2 \mathrm{bc}$ \\
\hline & 5 & $30,6 \mathrm{a}$ & $33,6 \mathrm{a}$ & $45,4 \mathrm{a}$ & $52,9 \mathrm{a}$ & $67,9 \mathrm{a}$ & $76,3 \mathrm{a}$ & $82,4 \mathrm{a}$ & 93,1 a \\
\hline \multicolumn{10}{|c|}{ C.V. $(\%)=5,8$} \\
\hline \multirow{5}{*}{ Folha Larga } & 6 & $38,4 \mathrm{a}$ & $43,9 \mathrm{a}$ & $52,3 \mathrm{a}$ & 63,3 a & $72,5 \mathrm{a}$ & $78,4 \mathrm{a}$ & $86,4 \mathrm{a}$ & 92,3 a \\
\hline & 7 & $84,2 \mathrm{~b}$ & $89,8 \mathrm{~b}$ & $90,0 \mathrm{~b}$ & $97,8 \mathrm{~b}$ & $98,7 \mathrm{~b}$ & $100,5 \mathrm{~b}$ & $109,3 \mathrm{~b}$ & $119,7 \mathrm{~b}$ \\
\hline & 8 & $41,2 \mathrm{a}$ & $46,4 \mathrm{a}$ & 52,6 a & $61,2 \mathrm{a}$ & $70,1 \mathrm{a}$ & $79,1 \mathrm{a}$ & $88,5 \mathrm{a}$ & $92,3 \mathrm{a}$ \\
\hline & 9 & $97,5 \mathrm{bc}$ & $102,0 \mathrm{bc}$ & $107,8 \mathrm{bc}$ & $120,6 \mathrm{bc}$ & $134,2 \mathrm{bc}$ & $139,4 \mathrm{bc}$ & $147,3 \mathrm{bc}$ & $161,5 \mathrm{bc}$ \\
\hline & 10 & $34,3 \mathrm{a}$ & $39,1 \mathrm{a}$ & $55,3 \mathrm{a}$ & $60,9 \mathrm{a}$ & $73,7 \mathrm{a}$ & $77,2 \mathrm{a}$ & $84,5 \mathrm{a}$ & 90,4 a \\
\hline \multicolumn{10}{|c|}{ C.V. $(\%)=6,2$} \\
\hline & & \multicolumn{3}{|c|}{ 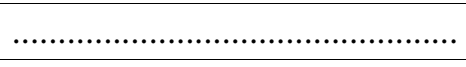 } & \multicolumn{2}{|c|}{50 sementes $/ 75 \mathrm{~mL}$} & \multicolumn{3}{|c|}{. } \\
\hline \multirow{5}{*}{ Cultivada } & 1 & $54,7 \mathrm{~b}$ & $56,6 \mathrm{bc}$ & $71,9 \mathrm{bc}$ & $81,8 \mathrm{bc}$ & $91,0 \mathrm{bc}$ & $98,6 \mathrm{bc}$ & $110,5 \mathrm{bc}$ & $117,1 \mathrm{bc}$ \\
\hline & 2 & $31,9 \mathrm{a}$ & $36,9 \mathrm{a}$ & $46,6 \mathrm{a}$ & 57,9 a & $66,7 \mathrm{a}$ & $73,1 \mathrm{a}$ & 83,6 a & $91,7 \mathrm{a}$ \\
\hline & 3 & $33,3 \mathrm{a}$ & $44,1 \mathrm{~b}$ & $59,3 \mathrm{~b}$ & $75,1 \mathrm{~b}$ & $87,0 \mathrm{~b}$ & $91,8 \mathrm{~b}$ & $99,7 \mathrm{~b}$ & $102,3 \mathrm{~b}$ \\
\hline & 4 & $50,1 \mathrm{~b}$ & $56,8 \mathrm{bc}$ & $69,9 \mathrm{bc}$ & 87,4 bc & $90,3 \mathrm{bc}$ & $101,3 \mathrm{bc}$ & $112,3 \mathrm{bc}$ & $125,2 \mathrm{bc}$ \\
\hline & 5 & $31,6 \mathrm{a}$ & $36,6 \mathrm{a}$ & $46,4 \mathrm{a}$ & 59,9 a & 69,9 a & 78,9 a & $83,4 \mathrm{a}$ & $94,1 \mathrm{a}$ \\
\hline \multicolumn{10}{|c|}{ C.V. $(\%)=5,0$} \\
\hline \multirow{5}{*}{ Folha Larga } & 6 & $38,4 \mathrm{a}$ & $44,9 \mathrm{a}$ & $54,3 \mathrm{a}$ & $66,3 \mathrm{a}$ & $73,5 \mathrm{a}$ & $80,4 \mathrm{a}$ & $86,4 \mathrm{a}$ & 94,3 a \\
\hline & 7 & $85,2 \mathrm{~b}$ & $90,8 \mathrm{~b}$ & $93,0 \mathrm{~b}$ & $99,0 \mathrm{~b}$ & $100,7 \mathrm{~b}$ & $103,5 \mathrm{~b}$ & $110,3 \mathrm{~b}$ & $120,7 \mathrm{~b}$ \\
\hline & 8 & $42,2 \mathrm{a}$ & $48,4 \mathrm{a}$ & 54,6 a & $64,2 \mathrm{a}$ & $71,1 \mathrm{a}$ & $80,1 \mathrm{a}$ & $91,5 \mathrm{a}$ & $93,3 \mathrm{a}$ \\
\hline & 9 & $97,5 \mathrm{bc}$ & $106,0 \mathrm{bc}$ & $112,8 \mathrm{bc}$ & $123,6 \mathrm{bc}$ & $136,2 \mathrm{bc}$ & $140,4 \mathrm{bc}$ & $149,3 \mathrm{bc}$ & $162,5 \mathrm{bc}$ \\
\hline & 10 & $42,3 \mathrm{a}$ & $45,1 \mathrm{a}$ & $56,3 \mathrm{a}$ & $62,9 \mathrm{a}$ & $71,7 \mathrm{a}$ & $79,2 \mathrm{a}$ & 89,5 a & $92,4 \mathrm{a}$ \\
\hline
\end{tabular}

Comparação de médias dentro de cada coluna pelo teste de Tukey não diferem entre si a 5\% de probabilidade. 
TABELA 4. Condutividade elétrica $\left(\mu \mathrm{S} . \mathrm{cm}^{-1} \mathrm{~g}^{-1}\right)$ utilizando as combinações 25 sementes $/ 50 \mathrm{~mL}$ e 50 sementes/50 mL, a $25{ }^{\circ} \mathrm{C}$, respectivamente, de dez lotes de sementes de rúcula, cultivares Cultivada e Folha Larga, em cada período de embebição.

\begin{tabular}{|c|c|c|c|c|c|c|c|c|c|}
\hline \multirow{3}{*}{ Cultivares } & \multirow{3}{*}{ Lotes } & \multicolumn{8}{|c|}{ Períodos de embebição (h) } \\
\hline & & 1 & 2 & 4 & 8 & 12 & 16 & 20 & 24 \\
\hline & & \multicolumn{3}{|c|}{ 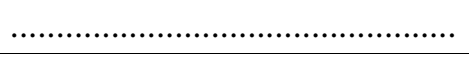 } & \multicolumn{2}{|c|}{25 sementes $/ 50 \mathrm{~mL}$} & \multicolumn{3}{|c|}{ 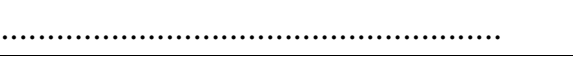 } \\
\hline \multirow{5}{*}{ Cultivada } & 1 & $58,7 \mathrm{~b}$ & $60,6 \mathrm{bc}$ & 79,9 bc & 90,8 bc & $93,0 \mathrm{bc}$ & $103,6 \mathrm{bc}$ & $113,5 \mathrm{bc}$ & $124,1 \mathrm{bc}$ \\
\hline & 2 & 35,9 a & 40,9 a & 54,6 a & $61,5 \mathrm{a}$ & $76,7 \mathrm{a}$ & $81,1 \mathrm{a}$ & 89,6 a & $92,7 \mathrm{a}$ \\
\hline & 3 & $37,3 \mathrm{a}$ & $49,1 \mathrm{~b}$ & $63,3 \mathrm{~b}$ & $76,1 \mathrm{~b}$ & $88,0 \mathrm{~b}$ & $95,8 \mathrm{~b}$ & $105,7 \mathrm{~b}$ & $108,3 \mathrm{~b}$ \\
\hline & 4 & $57,1 \mathrm{~b}$ & $63,8 \mathrm{bc}$ & $76,9 \mathrm{bc}$ & 91,4 bc & $95,3 \mathrm{bc}$ & $105,3 \mathrm{bc}$ & $112,3 \mathrm{bc}$ & $129,2 \mathrm{bc}$ \\
\hline & 5 & $36,6 \mathrm{a}$ & $41,6 \mathrm{a}$ & 50,4 a & 62,9 a & $70,9 \mathrm{a}$ & 82,9 a & $92,4 \mathrm{a}$ & $111,1 \mathrm{a}$ \\
\hline \multicolumn{10}{|c|}{ C.V. $(\%)=5,8$} \\
\hline \multirow{5}{*}{ Folha Larga } & 6 & $41,4 \mathrm{a}$ & 48,9 a & $57,3 \mathrm{a}$ & $70,3 \mathrm{a}$ & $77,5 \mathrm{a}$ & $82,4 \mathrm{a}$ & $94,4 \mathrm{a}$ & 99,9 a \\
\hline & 7 & $90,2 \mathrm{~b}$ & $92,8 \mathrm{~b}$ & $98,0 \mathrm{~b}$ & $101,0 \mathrm{~b}$ & $103,7 \mathrm{~b}$ & $106,5 \mathrm{~b}$ & $113,3 \mathrm{~b}$ & $123,7 \mathrm{~b}$ \\
\hline & 8 & $46,2 \mathrm{a}$ & $51,4 \mathrm{a}$ & $60,6 \mathrm{a}$ & $66,2 \mathrm{a}$ & $74,1 \mathrm{a}$ & $82,1 \mathrm{a}$ & $97,5 \mathrm{a}$ & $98,3 \mathrm{a}$ \\
\hline & 9 & $90,5 \mathrm{~b}$ & $99,0 \mathrm{bc}$ & $110,8 \mathrm{bc}$ & $128,6 \mathrm{bc}$ & $134,2 \mathrm{bc}$ & $143,4 \mathrm{bc}$ & $153,3 \mathrm{bc}$ & $159,5 \mathrm{bc}$ \\
\hline & 10 & $46,3 \mathrm{a}$ & $48,1 \mathrm{a}$ & $55,3 \mathrm{a}$ & 65,9 a & $75,7 \mathrm{a}$ & $84,2 \mathrm{a}$ & $98,5 \mathrm{a}$ & 99,4 a \\
\hline \multicolumn{10}{|c|}{ C.V. $(\%)=6,6$} \\
\hline & & \multicolumn{3}{|c|}{. } & \multicolumn{2}{|c|}{50 sementes $/ 50 \mathrm{~mL}$} & .................... & ................. & ......... \\
\hline & 1 & $60,7 \mathrm{~b}$ & $62,6 \mathrm{bc}$ & 77,9 bc & $97,8 \mathrm{c}$ & $99,0 \mathrm{c}$ & $105,6 \mathrm{c}$ & $116,5 \mathrm{c}$ & $129,1 \mathrm{c}$ \\
\hline & 2 & 37,9 a & $41,9 \mathrm{a}$ & $52,6 \mathrm{a}$ & $63,9 \mathrm{a}$ & $72,7 \mathrm{a}$ & $80,1 \mathrm{a}$ & 89,6 a & $98,7 \mathrm{a}$ \\
\hline Cultivada & 3 & $39,3 \mathrm{a}$ & $48,1 \mathrm{~b}$ & $65,3 \mathrm{~b}$ & $77,1 \mathrm{~b}$ & $91,0 \mathrm{~b}$ & $98,8 \mathrm{~b}$ & $104,7 \mathrm{~b}$ & $110,3 \mathrm{~b}$ \\
\hline & 4 & $56,1 \mathrm{~b}$ & $62,8 \mathrm{bc}$ & 75,9 bc & $93,4 \mathrm{c}$ & $97,3 \mathrm{c}$ & $107,3 \mathrm{c}$ & $119,3 \mathrm{c}$ & $132,2 \mathrm{c}$ \\
\hline & 5 & 37,6 a & $42,6 \mathrm{a}$ & $52,4 \mathrm{a}$ & 65,9 a & $74,9 \mathrm{a}$ & 84,9 a & $90,4 \mathrm{a}$ & $101,1 \mathrm{a}$ \\
\hline \multicolumn{10}{|c|}{ C.V. $(\%)=4,9$} \\
\hline \multirow{5}{*}{ Folha Larga } & 6 & $44,4 \mathrm{a}$ & 50,9 a & $60,3 \mathrm{a}$ & $71,3 \mathrm{a}$ & $79,5 \mathrm{a}$ & $85,4 \mathrm{a}$ & $92,4 \mathrm{a}$ & $98,3 \mathrm{a}$ \\
\hline & 7 & $91,2 \mathrm{~b}$ & $95,8 \mathrm{~b}$ & $100,0 \mathrm{~b}$ & $103,0 \mathrm{~b}$ & $104,7 \mathrm{~b}$ & $108,5 \mathrm{~b}$ & $114,3 \mathrm{~b}$ & $125,7 \mathrm{~b}$ \\
\hline & 8 & $48,2 \mathrm{a}$ & $52,4 \mathrm{a}$ & $61,6 \mathrm{a}$ & $68,2 \mathrm{a}$ & $75,1 \mathrm{~b}$ & $84,1 \mathrm{a}$ & $95,5 \mathrm{a}$ & $99,3 \mathrm{a}$ \\
\hline & 9 & $102,5 \mathrm{bc}$ & $112,0 \mathrm{bc}$ & $118,8 \mathrm{bc}$ & $130,6 \mathrm{c}$ & $140,2 \mathrm{c}$ & $144,4 \mathrm{c}$ & $153,3 \mathrm{c}$ & $167,5 \mathrm{c}$ \\
\hline & 10 & $38,3 \mathrm{a}$ & $45,1 \mathrm{a}$ & $53,3 \mathrm{a}$ & $67,9 \mathrm{a}$ & $76,7 \mathrm{a}$ & $83,2 \mathrm{a}$ & $91,5 \mathrm{a}$ & $97,4 \mathrm{a}$ \\
\hline
\end{tabular}

C.V. $(\%)=5,5$

Comparação de médias dentro de cada coluna pelo teste de Tukey não diferem entre si a 5\% de probabilidade. 
TABELA 5. Condutividade elétrica $\left(\mu \mathrm{S} . \mathrm{cm}^{-1} \mathrm{~g}^{-1}\right)$ utilizando as combinações 25 sementes $/ 75 \mathrm{~mL}$ e 50 sementes/75 mL, a $25^{\circ} \mathrm{C}$, respectivamente, de dez lotes de sementes de rúcula, cultivar Cultivada e Folha Larga, em cada período de embebição.

\begin{tabular}{|c|c|c|c|c|c|c|c|c|c|}
\hline \multirow{3}{*}{ Cultivares } & \multirow{3}{*}{ Lotes } & \multicolumn{8}{|c|}{ Períodos de embebição (h) } \\
\hline & & 1 & 2 & 4 & 8 & 12 & 16 & 20 & 24 \\
\hline & & & \multicolumn{4}{|c|}{..... 25 sementes $/ 75 \mathrm{~mL}$} & \\
\hline \multirow{5}{*}{ Cultivada } & 1 & $53,7 \mathrm{~b}$ & $54,6 \mathrm{bc}$ & $74,9 \mathrm{bc}$ & $82,8 \mathrm{bc}$ & 90,9 bc & 98,9 bc & $106,5 \mathrm{bc}$ & $124,1 \mathrm{bc}$ \\
\hline & 2 & $31,9 \mathrm{a}$ & 34,9 a & $46,6 \mathrm{a}$ & 57,9 a & 65,8 a & 73,8 a & 82,6 a & 93,7 a \\
\hline & 3 & $33,3 \mathrm{a}$ & $41,9 \mathrm{~b}$ & $59,3 \mathrm{~b}$ & $70,9 \mathrm{~b}$ & $85,0 \mathrm{~b}$ & $91,8 \mathrm{~b}$ & $98,7 \mathrm{~b}$ & $103,3 \mathrm{~b}$ \\
\hline & 4 & $49,9 \mathrm{~b}$ & $54,8 \mathrm{bc}$ & $69,9 \mathrm{bc}$ & 85,4 bc & $96,3 \mathrm{bc}$ & $100,8 \mathrm{bc}$ & $111,9 \mathrm{bc}$ & $125,4 \mathrm{bc}$ \\
\hline & 5 & 32,6 a & $38,6 \mathrm{ab}$ & $46,4 \mathrm{a}$ & 55,9 a & 68,9 a & $78,3 \mathrm{a}$ & $85,4 \mathrm{a}$ & $95,6 \mathrm{a}$ \\
\hline \multicolumn{10}{|l|}{ C.V. $(\%)=6,4$} \\
\hline \multirow{5}{*}{ Folha Larga } & 6 & $39,4 \mathrm{a}$ & $44,9 \mathrm{a}$ & $50,3 \mathrm{a}$ & $64,3 \mathrm{a}$ & $73,5 \mathrm{a}$ & $77,4 \mathrm{a}$ & 85,4 a & $95,3 \mathrm{a}$ \\
\hline & 7 & $85,2 \mathrm{~b}$ & $86,8 \mathrm{~b}$ & $91,0 \mathrm{~b}$ & $99,8 \mathrm{~b}$ & $100,7 \mathrm{~b}$ & $106,5 \mathrm{~b}$ & $108,3 \mathrm{~b}$ & $119,9 \mathrm{~b}$ \\
\hline & 8 & $43,2 \mathrm{a}$ & $47,4 \mathrm{a}$ & $50,6 \mathrm{a}$ & $62,2 \mathrm{a}$ & $71,1 \mathrm{a}$ & 79,9 a & $89,5 \mathrm{a}$ & 96,3 a \\
\hline & 9 & $96,5 \mathrm{bc}$ & $100,0 \mathrm{bc}$ & $106,8 \mathrm{bc}$ & $121,6 \mathrm{bc}$ & $130,2 \mathrm{bc}$ & $140,4 \mathrm{bc}$ & $146,3 \mathrm{bc}$ & $165,5 \mathrm{bc}$ \\
\hline & 10 & $37,3 \mathrm{a}$ & $45,1 \mathrm{a}$ & $48,3 \mathrm{a}$ & $68,9 \mathrm{a}$ & $72,7 \mathrm{a}$ & $79,2 \mathrm{a}$ & $86,5 \mathrm{a}$ & $96,4 \mathrm{a}$ \\
\hline \multicolumn{10}{|l|}{ C.V. $(\%)=7,7$} \\
\hline & & \multicolumn{3}{|c|}{. } & \multicolumn{2}{|c|}{50 sementes/75 mL } & ................... & ................... & \\
\hline & 1 & $54,7 \mathrm{~b}$ & $53,6 \mathrm{bc}$ & $75,9 \mathrm{bc}$ & $83,8 \mathrm{bc}$ & $96,9 \mathrm{bc}$ & 99,9 bc & $109,5 \mathrm{bc}$ & $125,1 \mathrm{bc}$ \\
\hline & 2 & 32,9 a & $36,9 \mathrm{a}$ & $47,6 \mathrm{a}$ & 54,9 a & $66,8 \mathrm{a}$ & 77,8 a & 83,6 a & $94,7 \mathrm{a}$ \\
\hline Cultivada & 3 & $34,3 \mathrm{a}$ & $42,9 \mathrm{~b}$ & $58,3 \mathrm{~b}$ & $71,9 \mathrm{~b}$ & $87,0 \mathrm{~b}$ & $96,8 \mathrm{~b}$ & $99,7 \mathrm{~b}$ & $104,3 \mathrm{~b}$ \\
\hline & 4 & $48,9 \mathrm{~b}$ & $55,8 \mathrm{bc}$ & $68,9 \mathrm{bc}$ & 86,4 bc & $98,3 \mathrm{bc}$ & $100,0 \mathrm{bc}$ & $112,9 \mathrm{bc}$ & $126,4 \mathrm{bc}$ \\
\hline & 5 & $33,6 \mathrm{a}$ & 39,6 a & $47,4 \mathrm{a}$ & 56,9 a & $67,9 \mathrm{a}$ & $77,2 \mathrm{a}$ & 84,4 a & 96,6 a \\
\hline \multicolumn{10}{|l|}{ C.V. $(\%)=5,0$} \\
\hline \multirow{5}{*}{ Folha Larga } & 6 & 39,9 a & $45,9 \mathrm{a}$ & $55,3 \mathrm{a}$ & $67,3 \mathrm{a}$ & $76,5 \mathrm{a}$ & $76,4 \mathrm{a}$ & $86,4 \mathrm{a}$ & 96,3 a \\
\hline & 7 & $86,2 \mathrm{~b}$ & $87,8 \mathrm{~b}$ & $93,0 \mathrm{~b}$ & $98,8 \mathrm{~b}$ & $102,7 \mathrm{~b}$ & $108,5 \mathrm{~b}$ & $110,3 \mathrm{~b}$ & $112,9 \mathrm{~b}$ \\
\hline & 8 & $40,2 \mathrm{a}$ & $48,4 \mathrm{a}$ & 54,6 a & $63,2 \mathrm{a}$ & 76,1 a & 78,9 a & $87,5 \mathrm{a}$ & 93,3 a \\
\hline & 9 & $90,5 \mathrm{~b}$ & $103,0 \mathrm{bc}$ & $113,8 \mathrm{bc}$ & $120,6 \mathrm{bc}$ & $128,2 \mathrm{bc}$ & $138,4 \mathrm{bc}$ & $145,3 \mathrm{bc}$ & $160,5 \mathrm{bc}$ \\
\hline & 10 & $38,3 \mathrm{a}$ & $43,1 \mathrm{a}$ & $51,3 \mathrm{a}$ & $63,9 \mathrm{a}$ & 78,7 a & $76,2 \mathrm{a}$ & $88,5 \mathrm{a}$ & $93,4 \mathrm{a}$ \\
\hline
\end{tabular}

Comparação de médias dentro de cada coluna pelo teste de Tukey não diferem entre si a 5\% de probabilidade. 
TABELA 6. Condutividade elétrica $\left(\mu \mathrm{S} . \mathrm{cm}^{-1} \mathrm{~g}^{-1}\right)$ utilizando as combinações 25 sementes $/ 50 \mathrm{~mL}$ e 50 sementes/50 mL, a $30{ }^{\circ} \mathrm{C}$, respectivamente, de dez lotes de sementes de rúcula, cultivar Cultivada e Folha Larga, em cada período de embebição.

\begin{tabular}{|c|c|c|c|c|c|c|c|c|c|}
\hline \multirow{3}{*}{ Cultivares } & \multirow{3}{*}{ Lotes } & \multicolumn{8}{|c|}{ Períodos de embebição (h) } \\
\hline & & 1 & 2 & 4 & 8 & 12 & 16 & 20 & 24 \\
\hline & & \multicolumn{3}{|c|}{. } & \multicolumn{5}{|c|}{25 sementes $/ 50 \mathrm{~mL}$} \\
\hline \multirow{5}{*}{ Cultivada } & 1 & $63,7 \mathrm{~b}$ & $65,6 \mathrm{~b}$ & $78,9 \mathrm{bc}$ & $100,8 \mathrm{bc}$ & $102,0 \mathrm{bc}$ & $107,6 \mathrm{bc}$ & $119,5 \mathrm{bc}$ & $132,1 \mathrm{bc}$ \\
\hline & 2 & $40,9 \mathrm{a}$ & $44,9 \mathrm{a}$ & $55,6 \mathrm{a}$ & $66,9 \mathrm{a}$ & $77,7 \mathrm{a}$ & 84,1 a & $102,6 \mathrm{a}$ & $100,7 \mathrm{a}$ \\
\hline & 3 & $42,3 \mathrm{a}$ & $62,1 \mathrm{~b}$ & $67,3 \mathrm{~b}$ & $76,1 \mathrm{~b}$ & $93,0 \mathrm{~b}$ & $101,8 \mathrm{~b}$ & $107,7 \mathrm{~b}$ & $112,3 \mathrm{~b}$ \\
\hline & 4 & $59,1 \mathrm{~b}$ & $64,8 \mathrm{~b}$ & $76,9 \mathrm{bc}$ & $97,4 \mathrm{bc}$ & $102,3 \mathrm{bc}$ & $110,3 \mathrm{bc}$ & $122,3 \mathrm{bc}$ & $135,2 \mathrm{bc}$ \\
\hline & 5 & 39,6 a & $43,6 \mathrm{a}$ & $53,4 \mathrm{a}$ & $66,9 \mathrm{a}$ & $75,9 \mathrm{a}$ & 85,9 a & $99,4 \mathrm{a}$ & $104,1 \mathrm{a}$ \\
\hline \multicolumn{10}{|c|}{ C.V. $(\%)=5,9$} \\
\hline \multirow{5}{*}{$\begin{array}{l}\text { Folha } \\
\text { Larga }\end{array}$} & 6 & $45,4 \mathrm{a}$ & 51,9 a & $61,3 \mathrm{a}$ & $72,3 \mathrm{a}$ & $79,5 \mathrm{a}$ & 86,4 a & $93,4 \mathrm{a}$ & 99,3 a \\
\hline & 7 & $92,2 \mathrm{~b}$ & $96,8 \mathrm{~b}$ & $101,0 \mathrm{~b}$ & $104,0 \mathrm{~b}$ & $105,7 \mathrm{~b}$ & $109,5 \mathrm{~b}$ & $115,3 \mathrm{~b}$ & $126,7 \mathrm{~b}$ \\
\hline & 8 & $47,2 \mathrm{a}$ & $53,4 \mathrm{a}$ & $62,6 \mathrm{a}$ & $69,2 \mathrm{a}$ & $76,1 \mathrm{~b}$ & $87,1 \mathrm{a}$ & $95,5 \mathrm{a}$ & $100,3 \mathrm{a}$ \\
\hline & 9 & $103,5 \mathrm{bc}$ & $113,0 \mathrm{bc}$ & $119,8 \mathrm{bc}$ & $131,6 \mathrm{bc}$ & $141,2 \mathrm{bc}$ & $145,4 \mathrm{bc}$ & $154,3 \mathrm{bc}$ & $168,5 \mathrm{bc}$ \\
\hline & 10 & $42,3 \mathrm{a}$ & $48,1 \mathrm{a}$ & 57,3 a & $68,9 \mathrm{a}$ & $77,7 \mathrm{a}$ & $89,2 \mathrm{a}$ & $92,5 \mathrm{a}$ & $99,4 \mathrm{a}$ \\
\hline \multicolumn{10}{|c|}{ C.V. $(\%)=6,3$} \\
\hline \multicolumn{10}{|c|}{50 sementes $/ 50 \mathrm{~mL}$} \\
\hline \multirow{5}{*}{ Cultivada } & 1 & $65,7 \mathrm{~b}$ & $67,6 \mathrm{~b}$ & 82,9 bc & $102,8 \mathrm{bc}$ & $104,0 \mathrm{bc}$ & $115,6 \mathrm{bc}$ & $121,5 \mathrm{~b}$ & $134,1 \mathrm{~b}$ \\
\hline & 2 & $42,9 \mathrm{a}$ & $46,9 \mathrm{a}$ & $57,6 \mathrm{a}$ & $68,3 \mathrm{a}$ & $79,7 \mathrm{a}$ & $85,1 \mathrm{a}$ & $104,6 \mathrm{a}$ & $113,7 \mathrm{a}$ \\
\hline & 3 & $44,3 \mathrm{a}$ & $63,1 \mathrm{~b}$ & $69,3 \mathrm{~b}$ & $78,1 \mathrm{~b}$ & $95,0 \mathrm{~b}$ & $103,8 \mathrm{~b}$ & $105,7 \mathrm{a}$ & 114,3 a \\
\hline & 4 & $63,1 \mathrm{~b}$ & $66,8 \mathrm{~b}$ & 79,9 bc & 98,4 bc & $104,3 \mathrm{bc}$ & $118,3 \mathrm{bc}$ & $124,3 \mathrm{~b}$ & $137,2 \mathrm{~b}$ \\
\hline & 5 & $40,6 \mathrm{a}$ & $45,6 \mathrm{a}$ & $55,4 \mathrm{a}$ & 67,9 a & 77,9 a & 87,9 a & 99,4 a & $111,1 \mathrm{a}$ \\
\hline \multicolumn{10}{|c|}{ C.V. $(\%)=4,3$} \\
\hline \multirow{5}{*}{$\begin{array}{l}\text { Folha } \\
\text { Larga }\end{array}$} & 6 & $47,4 \mathrm{a}$ & 53,9 a & $63,3 \mathrm{a}$ & $74,3 \mathrm{a}$ & $81,5 \mathrm{a}$ & $89,4 \mathrm{a}$ & $95,4 \mathrm{a}$ & $101,3 \mathrm{a}$ \\
\hline & 7 & $94,2 \mathrm{~b}$ & $98,8 \mathrm{~b}$ & $103,0 \mathrm{~b}$ & $106,0 \mathrm{~b}$ & $107,7 \mathrm{~b}$ & $111,5 \mathrm{~b}$ & $117,3 \mathrm{~b}$ & $128,7 \mathrm{~b}$ \\
\hline & 8 & $51,2 \mathrm{a}$ & $55,4 \mathrm{a}$ & $64,6 \mathrm{a}$ & $71,2 \mathrm{a}$ & $78,1 \mathrm{~b}$ & 87,1 a & $98,5 \mathrm{a}$ & $102,3 \mathrm{a}$ \\
\hline & 9 & $105,5 b c$ & $115,0 \mathrm{bc}$ & $121,8 \mathrm{bc}$ & $133,6 \mathrm{bc}$ & $143,2 \mathrm{bc}$ & $147,4 \mathrm{bc}$ & $156,3 \mathrm{bc}$ & $170,5 \mathrm{bc}$ \\
\hline & 10 & $46,3 \mathrm{a}$ & $49,1 \mathrm{a}$ & $62,3 \mathrm{a}$ & $70,9 \mathrm{a}$ & $79,7 \mathrm{a}$ & $90,2 \mathrm{a}$ & $94,5 \mathrm{a}$ & $100,4 \mathrm{a}$ \\
\hline
\end{tabular}

Comparação de médias dentro de cada coluna pelo teste de Tukey não diferem entre si a $5 \%$ de probabilidade. 
TABELA 7. Condutividade elétrica $\left(\mu \mathrm{S} . \mathrm{cm}^{-1} \mathrm{~g}^{-1}\right)$ utilizando as combinações 25 sementes $/ 75 \mathrm{~mL}$ e 50 sementes/75 mL, a $30{ }^{\circ} \mathrm{C}$, respectivamente, de dez lotes de sementes de rúcula, cultivar Cultivada e Folha Larga, em cada período de embebição.

\begin{tabular}{|c|c|c|c|c|c|c|c|c|c|}
\hline \multirow{3}{*}{ Cultivares } & \multirow[b]{2}{*}{ Lotes } & \multicolumn{8}{|c|}{ Períodos de embebição (h) } \\
\hline & & 1 & 2 & 4 & 8 & 12 & 16 & 20 & 24 \\
\hline & \multicolumn{9}{|c|}{. 25 sementes $/ 75 \mathrm{~mL}$} \\
\hline \multirow{5}{*}{ Cultivada } & 1 & $55,7 \mathrm{~b}$ & $57,6 \mathrm{bc}$ & $75,9 \mathrm{bc}$ & 86,8 bc & 92,9 bc & 99,9 bc & $108,5 \mathrm{bc}$ & $125,1 \mathrm{bc}$ \\
\hline & 2 & $32,9 \mathrm{a}$ & 35,9 a & 47,6 a & 58,9 a & $68,8 \mathrm{a}$ & 74,8 a & 84,6 a & 98,7 a \\
\hline & 3 & $35,3 \mathrm{a}$ & $42,9 \mathrm{~b}$ & $59,9 \mathrm{~b}$ & $72,9 \mathrm{~b}$ & $88,0 \mathrm{~b}$ & $93,8 \mathrm{~b}$ & $99,7 \mathrm{~b}$ & $104,3 \mathrm{~b}$ \\
\hline & 4 & $48,9 \mathrm{~b}$ & $56,8 \mathrm{bc}$ & $68,9 \mathrm{bc}$ & $86,4 \mathrm{bc}$ & 97,3 bc & $107,8 \mathrm{bc}$ & $112,9 \mathrm{bc}$ & $127,4 \mathrm{bc}$ \\
\hline & 5 & $35,6 \mathrm{a}$ & $39,6 \mathrm{a}$ & $47,4 \mathrm{a}$ & 56,9 a & $69,9 \mathrm{a}$ & $79,3 \mathrm{a}$ & $86,4 \mathrm{a}$ & 94,6 a \\
\hline \multicolumn{10}{|c|}{ C.V. $(\%)=5,8$} \\
\hline \multirow{5}{*}{$\begin{array}{l}\text { Folha } \\
\text { Larga }\end{array}$} & 6 & 39,9 a & 45,9 a & 52,3 a & $65,3 \mathrm{a}$ & $72,5 \mathrm{a}$ & $81,4 \mathrm{a}$ & 89,4 a & 99,3 a \\
\hline & 7 & $86,2 \mathrm{~b}$ & $89,8 \mathrm{~b}$ & $92,0 \mathrm{~b}$ & $98,8 \mathrm{~b}$ & $102,7 \mathrm{~b}$ & $109,5 \mathrm{~b}$ & $109,3 \mathrm{~b}$ & $120,9 \mathrm{~b}$ \\
\hline & 8 & $44,2 \mathrm{a}$ & $49,4 \mathrm{a}$ & 52,6 a & $65,9 \mathrm{a}$ & $74,1 \mathrm{a}$ & 83,9 a & 93,5 a & 99,3 a \\
\hline & 9 & $97,5 \mathrm{bc}$ & $102,0 \mathrm{bc}$ & $108,8 \mathrm{bc}$ & $122,6 \mathrm{bc}$ & $132,2 \mathrm{bc}$ & $144,4 \mathrm{bc}$ & $149,3 \mathrm{bc}$ & $173,5 \mathrm{bc}$ \\
\hline & 10 & $38,3 \mathrm{a}$ & $45,1 \mathrm{a}$ & 49,6 a & 69,9 a & $78,7 \mathrm{a}$ & $85,2 \mathrm{a}$ & 89,5 a & $99,4 \mathrm{a}$ \\
\hline \multicolumn{10}{|c|}{ C.V. $(\%)=6,4$} \\
\hline \multicolumn{10}{|c|}{. } \\
\hline \multirow{5}{*}{ Cultivada } & 1 & $48,7 \mathrm{~b}$ & $49,6 \mathrm{~b}$ & $78,9 \mathrm{bc}$ & 89,8 bc & 98,9 bc & $104,9 \mathrm{bc}$ & $113,5 \mathrm{bc}$ & $119,1 \mathrm{bc}$ \\
\hline & 2 & $33,9 \mathrm{a}$ & $38,9 \mathrm{a}$ & 49,6 a & 59,9 a & $69,8 \mathrm{a}$ & $78,8 \mathrm{a}$ & 87,6 a & 99,7 a \\
\hline & 3 & $36,3 \mathrm{a}$ & $44,9 \mathrm{~b}$ & $64,9 \mathrm{~b}$ & $77,9 \mathrm{~b}$ & $89,0 \mathrm{~b}$ & $99,8 \mathrm{~b}$ & $101,7 \mathrm{~b}$ & $105,3 \mathrm{~b}$ \\
\hline & 4 & $47,9 \mathrm{~b}$ & $48,8 \mathrm{~b}$ & $69,9 \mathrm{bc}$ & 88,4 bc & $99,3 \mathrm{bc}$ & $109,8 \mathrm{bc}$ & $119,9 \mathrm{bc}$ & $129,4 \mathrm{bc}$ \\
\hline & 5 & $38,6 \mathrm{a}$ & $42,6 \mathrm{a}$ & $48,4 \mathrm{a}$ & 58,9 a & $70,9 \mathrm{a}$ & $80,3 \mathrm{a}$ & 89,4 a & 99,9 a \\
\hline \multicolumn{10}{|c|}{ C.V. $(\%)=4,0$} \\
\hline \multirow{5}{*}{$\begin{array}{l}\text { Folha } \\
\text { Larga }\end{array}$} & 6 & $46,9 \mathrm{a}$ & $49,9 \mathrm{a}$ & $58,3 \mathrm{a}$ & $79,3 \mathrm{a}$ & $72,5 \mathrm{a}$ & 89,4 a & 96,4 a & $100,3 \mathrm{a}$ \\
\hline & 7 & $96,2 \mathrm{~b}$ & $99,8 \mathrm{~b}$ & $100,0 \mathrm{~b}$ & $110,8 \mathrm{~b}$ & $131,7 \mathrm{~b}$ & $129,5 \mathrm{~b}$ & $139,3 \mathrm{~b}$ & $138,9 \mathrm{~b}$ \\
\hline & 8 & $45,2 \mathrm{a}$ & $59,4 \mathrm{a}$ & $62,6 \mathrm{a}$ & $76,2 \mathrm{a}$ & $76,1 \mathrm{a}$ & 89,9 a & $94,5 \mathrm{a}$ & 99,9 a \\
\hline & 9 & $98,5 \mathrm{~b}$ & $108,0 \mathrm{~b}$ & $120,8 \mathrm{bc}$ & $128,6 \mathrm{bc}$ & $136,2 \mathrm{~b}$ & $149,4 \mathrm{bc}$ & $152,3 \mathrm{bc}$ & $163,5 b c$ \\
\hline & 10 & $41,3 \mathrm{a}$ & $49,1 \mathrm{a}$ & $59,3 \mathrm{a}$ & $75,9 \mathrm{a}$ & 78,7 a & 88,2 a & $98,5 \mathrm{a}$ & $100,4 \mathrm{a}$ \\
\hline
\end{tabular}

Comparação de médias dentro de cada coluna pelo teste de Tukey não diferem entre si a 5\% de probabilidade.

Com relação ao período de embebição das sementes, verificou-se para ambos os cultivares, nas diversas combinações, aumento progressivo das leituras com o decorrer do período de embebição o que se mostra coerente com as observações de Oliveira e Novembre (2005), Dutra e Vieira (2006) e Alves e Sá (2009). Observou-se que todos os procedimentos apresentaram significativa lixiviação após o período inicial de uma hora de embebição, permitindo estratificação dos lotes quanto ao potencial fisiológico. Entretanto, essa classificação dos lotes, para ambos os cultivares, tornou-se mais evidente após o período de oito horas de embebição, onde os valores de condutividade elétrica indicaram a possibilidade de separar lotes em diferentes níveis de vigor, com redução no período de condicionamento das sementes, principalmente, quando se utilizou a combinação 50 sementes, em $50 \mathrm{~mL}$ de água desionizada, a $25^{\circ} \mathrm{C}$. Essa possibilidade de redução do período de 
condicionamento das sementes também foi constatada por Torres et al. (1998), com sementes de maxixe, Oliveira e Novembre (2005), com sementes de pimentão, Dutra e Vieira (2006), com sementes de abobrinha, e Alves e Sá (2009), com sementes de rúcula.

No tocante ao número de sementes, em geral, verificouse que, mantendo constantes a temperatura, o volume e período de embebição os valores de lixiviação tiveram pequenos aumentos em função do aumento do número de sementes, para ambos os cultivares, nas diversas combinações. Portanto, para reduzir a variabilidade e obter resultados mais consistentes, recomenda-se o uso de quatro repetições de 50 sementes (Loeffler et al., 1988; Hampton et al., 1992). Nesse sentido, constatou-se que as combinações de 50 sementes, em ambos os cultivares, apresentaram coeficiente de variação médio de 4,9\%, enquanto que o de 25 sementes foi de 6,2\%. Baseado neste fato, recomenda-se o emprego de quatro repetições de 50 sementes de rúcula para a condução do teste de condutividade elétrica, concordando com os resultados de Alves e Sá (2009), também, com sementes de rúcula.

Constatou-se que a elevação da temperatura de 20 para 25 ou $30{ }^{\circ} \mathrm{C}$ proporcionou aumento da lixiviação dos exsudatos, mas manteve as tendências ordenadas de acréscimo dos lixiviados durante os períodos de embebição, sem alterar a classificação dos lotes. Segundo Matthews e Powell (1981), Marcos Filho et al. (1987), Krzyzanowski et al. (1991) e Hampton e TeKrony (1995) a temperatura de $20^{\circ} \mathrm{C}$ ainda é comum no condicionamento das sementes para o teste de condutividade elétrica. Porém, considerando os efeitos das temperaturas de embebição e de avaliação, recomenda-se o uso de $25^{\circ} \mathrm{C}$, por ser esta temperatura mais coerente com as condições ambientais dos laboratórios de análise de sementes em países de clima tropical, como o Brasil, ou seja, essa temperatura está, normalmente, mais próxima das condições internas, do que as de $20{ }^{\circ} \mathrm{C}$ e $30{ }^{\circ} \mathrm{C}$ (Vieira e Krzyzanowski, 1999). No presente estudo, verificouse que a temperatura de $25^{\circ} \mathrm{C}$ foi a mais adequada para condução do teste de condutividade elétrica em sementes de rúcula, principalmente associada ao volume de $50 \mathrm{~mL}$ de água destilada.

Verificou-se que a redução do volume de água, quando se mantiveram constantes os outros fatores (número de sementes, temperatura e período de embebição), estabeleceu, em geral, relação direta com o aumento do valor da lixiviação. Essa tendência foi observada para os dois cultivares estudados nos diferentes procedimentos; os valores de lixiviação, no menor volume, foram superiores ou próximos aos do tratamento com maior volume. Esse fato concorda com os verificados por Lopes e Franke (2010), quando trabalharam com sementes de azevém. Portanto, em função dos volumes 50 e $75 \mathrm{~mL}$, fornecerem resultados similares de condutividade elétrica, adotouse o volume de $50 \mathrm{~mL}$, tendo em vista o tamanho das sementes de rúcula. Resultados semelhantes, também, foram encontrados por Alves e Sá (2009) com sementes de rúcula.

\section{CONCLUSÃO}

O teste de condutividade elétrica é eficiente para avaliação do vigor de sementes de rúcula quando conduzido com 50 sementes imersas em $50 \mathrm{~mL}$ de água desionizada a $25^{\circ} \mathrm{C}$, após oito horas de embebição.

\section{AGRADECIMENTOS}

Os autores agradecem à empresa ISLA Sementes Ltda, na pessoa da Engenheira Agrônoma Juliana R. Trinca, por ceder as sementes utilizadas neste experimento.

Ao Conselho Nacional de Desenvolvimento Científico e Tecnológico (CNPq) pela bolsa concedida ao primeiro autor.

\section{REFERÊNCIAS}

ALVES, C.Z.; SÁ, M.E. Teste de condutividade elétrica na avaliação do vigor de sementes de rúcula. Revista Brasileira de Sementes, v.31, n.1, p.203-215, 2009.

BHÉRING, M.C.; DIAS, D.C.F.S.; GOMES, J.M.; BARROS, D.I. Métodos para avaliação do vigor de sementes de pepino. Revista Brasileira de Sementes, v.22, n.2, p.171-175, 2000.

BRASIL. Ministério da Agricultura e Reforma Agrária. Secretaria Nacional de Defesa Agropecuária. Departamento Nacional de Produção Vegetal. Coordenação de Laboratório Vegetal. Regras para Análise de Sementes. Brasília, DF, 1992. 365p.

CARVALHO, N.M.; NAKAGAWA, J. Sementes: ciência, tecnologia e produção. 4.ed. Jaboticabal: Funep, 2000. $588 \mathrm{p}$.

DIAS， D.C.F.S.; VIEIRA， A.N.; BHÉRING， M.C. Condutividade elétrica e lixiviação de potássio para avaliação do vigor de sementes de hortaliças: feijão-de- 
vagem e quiabo. Revista Brasileira de Sementes, v.20, n.2, p.408-413, 1998.

DUTRA, A.S.; VIEIRA, R.D. Teste de condutividade elétrica para avaliação do vigor de sementes de abrobrinha. Revista Brasileira de Sementes, v.28, n.2, p.117-122, 2006.

GOULART, L.S.; TILLMANN, M.A.A. Vigor de sementes de rúcula (Eruca sativa L.) pelo teste de deterioração controlada. Revista Brasileira de Sementes, v.29, n.2, p.179-186, 2007.

HAMPTON, J.G.; JONHSTONE, K.A.; EUA-UMPON, V. Bulk conductivity test variables for mungbean, soybean and French bean seed lots. Seed Science and Technology, v.20, n.3, p.677-686, 1992.

HAMPTON, J.G.; TEKRONY, D.M. Handbook of vigor test methods. Zürich: ISTA, 1995. 117p.

KRZYZANOWSKI, F.C.; FRANÇA NETO, J.B.; HENNING, A.A. Relato dos testes de vigor disponíveis para grandes culturas. Informativo ABRATES, v.1, n.2, p.15-50, 1991.

KULIK, M.M.; YAKLICH, R.W. Evaluation for vigor tests in soybean seeds relationship of accelerated aging, cold, sand bench and speed of germination tests to field performance. Crop Science, v.22, n.4, p.776-770, 1982.

LOEFFLER, T.M.; TEKRONY, D.M.; EGLI, D.B. The bulk conductivity test as an indicator of soybean seed quality. Journal of Seed Technology, v.12, n.1, p.37-53, 1988.

LOPES, R.R.; FRANKE, L.B. Teste de condutividade elétrica para avaliação da qualidade fisiológica de sementes de azevém (Lolium multiflorum L.). Revista Brasileira de Sementes, v.32, n.1, p.123-130, 2010.

MARCOS FILHO, J. Fisiologia de sementes de plantas cultivadas. Piracicaba: FEALQ, 2005. 495p.

MARCOS FILHO, J. O valor dos testes de vigor. Seed News, n.6, p.32, jul/ago. 1998.

MARCOS FILHO, J. Testes de vigor: importância e utilização. In: KRZYZANOWSKI, F.C.; VIEIRA, R.D.; FRANÇA NETO, J.B. (Ed.). Vigor de sementes: conceitos e testes. Londrina: ABRATES, 1999a. cap.1, p.1-21.

MARCOS FILHO, J.; CICERO, S.M.; SILVA, W.R. Avaliação da qualidade das sementes. Piracicaba: FEALQ, 1987. 230p.

MARCOS FILHO, J.; PESCARIN, H.M.C.; KOMATSU, Y.H.; DEMÉTRIO, C.G.B.; FANCELLI, A.L. Testes para avaliação do vigor de sementes de soja e suas relações com a emergência das plântulas em campo. Pesquisa Agropecuária Brasileira, v.19, n.5, p.605-613, 1984.

MARCOS FILHO, J.; VIEIRA, R.D. Seed vigor tests: Procedures - Conductivity test. In: BAALBAKI, R,; ELIAS, S.; MARCOS FILHO, J., MCDONALD, M.B. (Org.). Seed Vigor Test Handbook. Ithaca, NY. USA:AOSA. 2009. p.186-200.

MATTHEWS, S.; BRADNOCK, W.T. The detection of seed samples of wrinkleseed peas (Pisum sativum L.) of potentially low planting value. Proceedings of the International Seed Testing Association, v.32, p.553-563, 1967.

MATTHEWS, S.; POWELL, A.A. Electrical conductivity test. In: PERRY, D.A. (Ed.). Handbook of vigour test methods. Zürich: ISTA, 1981. p.37-42.

McDONALD, M.B.; PHANEENDRANATH, B.R. A modified accelerated aging vigor test procedure. Journal of Seed Technology, v.3, p.27-37, 1978.

NAKAGAWA, J. Testes de vigor baseados na avaliação das plântulas. In: VIEIRA, R.D.; CARVALHO, N.M. (Ed.). Testes de vigor de sementes. Jaboticabal: Funep, 1994. p.49-85.

OLIVEIRA, S.R.S.; NOVEMBRE, A.D.L.C. Teste de condutividade elétrica para as sementes de pimentão. Revista Brasileira de Sementes, v.27, n.1, p.31-36, 2005.

PANOBIANCO, M.; MARCOS FILHO, J. Evaluation of the physiological potentital of tomato sedds by germination and vigor tests. Seed Technology, v.23, n.2, p.151-161, 2001.

PANOBIANCO, M.; VIEIRA, R.D. Electrical conductivity os soaked soybean seeds: I. Effect of genotype. Pesquisa Agropecuária Brasileira, v.31, n.9, p.621-627, 1996.

PERRY, D.A. Report of vigour test committee 1979-1980. Seed Science and Technology, v.9, n.1, p.115-126, 1981.

POWELL, A.A. Cell membranes and seed leakage conductivity in relation to the quality of seed for sowing. Journal Seed Technology, v.10, n.2, p.81-100, 1986.

RAMOS, N.P.; FLOR, E.P.O.; MENDONÇA, E.A.F.; MINAMI, K. Envelhecimento acelerado em sementes de rúcula (Eruca sativa L.). Revista Brasileira de Sementes, v.26, n.1, p.98-103, 2004.

RODO, M.A.B.; MARCOS FILHO, J. Onion seed vigor in relation to plant growth and yield. Horticultura Brasileira, v.21, n.2, p.220-226, 2003. 
TEKRONY, D.M.; EGLI, D.B. Relationship between laboratory indices of soybean seed vigor and field emergence. Crop Science, v.17, n.4, p.573-577, 1977.

TORRES, S.B.; MARCOS FILHO, J. Physiological potential evaluation in melon seeds (Cucumis melo L.). Seed Science and Technology, v.33, n.2, p.341-350, 2005.
TORRES, S.B.; CASEIRO, R.F.; RODO, A.B.; MARCOS FILHO, J. Testes de vigor em sementes de maxixe (Cucumis anguria L.) com ênfase ao teste de condutividade elétrica. Revista Brasileira de Sementes, v.20, n.2, p.480-483, 1998.

VIEIRA, R.D.; KRZYZANOWSKI, F.C. Teste de condutividade elétrica. In: KRZYZANOWSKI, F.C.; VIEIRA, R.D.; FRANÇA NETO, J.B. (Ed.). Vigor de sementes: conceitos e testes. Londrina: ABRATES, 1999. cap.4, p.1-26. 